\title{
Reality of Educational Thought and Its Role in Social Change in Jordan from the Perspective of Educational Experts: A Qualitative Study
}

\author{
Shuangxin Xu Mohammad Amin Al-Qudah
}

\begin{abstract}
The present study aimed to explore the reality of educational thought in Jordan and its role in making social change from the perspective of experts in education. A qualitative approach is adopted. In-depth interviews were conducted with experts in the field education in Jordan (i.e. a former minister of the Ministry of Education, 3 faculty members specialized in education and 2 university presidents). It was found that educational thought in Jordan led to making several positive social changes, such positive changes include as follows: change in the value, moral, behavioral and economic system, a much more positive attitude towards education of woman, a change to what is considered taboo in professions, meanwhile negative changes such as loss of Jordanian identity and unemployment is deeply concerned. Regarding the reality of the (educational thought) in Jordan, the dominant educational thought in Jordan today is a mixture of different trends, affected by the western ideologies and thoughts due to globalization, with the respect of Islamic fundamental principles.
\end{abstract}

Keywords: educational thought, Jordan, social change.

DOI: $10.7176 / \mathrm{JEP} / 11-30-10$

Publication date:October $31^{\text {st }} 2020$

\section{Introduction:}

Educational thought is part of the human thought in general. It consists of a set of elements related to the educational process. Those elements are related to the teacher, student, curricula, teaching methods, educational administration, schools etc.. Educational thought may be defined as part of the creative human thought that is characterized with being dynamic. It keeps developing in on ongoing manner. It is based on the society's history, philosophy, culture, characteristics and needs (Shareef, 1940, p.239). It is possible to say that educational thought is the spirit of education, and it plays a fundamental role in defining the features of society as it is a blueprint for answering the question about the nature of the individuals we seek to educate and in what form we want our societies to be.

The educational thought, despite being a form of thought, it constitutes the mirror that reflects the movement of society in its various circumstances: economic, social, political and cultural... in addition to being affecting and influenced by society, it enriches society with its conditions, problems and impulses to amend negatively. It may negatively or positively affect the structure, trends and attitudes of society; it is affected by society as a part of it and as a child of it, so the relationship between them is an interrelated dialectical relationship. (Al-Abdullah, 2011)

In general, this dialectical relationship is represented in preserving the past heritage and cultural specificity of societies on the one hand, and renewing the contents of their culture and forming new cultural elements in order to preserve the vitality and continuity of society on the other hand. This role is almost paradoxical, as how can education lead to preserving and denying the past at the same time? This question has aroused controversy and interest from community reformers and educational scholars since ancient times. Sometimes the balance of the educational role tends to be more conservative than its regenerative role, and other times it tends to be more reformist and regenerative than preserving the past. These movements depend on the educational thought that prevails in society during a particular historical period.

Social Change, a concept of sociology, is considered a relatively recent term as a scientific study, and it is one of the central problems in sociology. There are several important definitions in the field of social change. For instance, Ginsberg (1958) defines social change as a change to the social structure of society. Such changes may include changes to the size or composition of the society, and changes to the pattern of balance between the society's parts. Examples of this type of change are the diminution of family size and the disintegration of the livelihood economy following the emergence of cities, and the shift from occupational sects to classes. (p: 205) Moore (1969) defines social change as any dramatic change to the social structure or pattern. Social changes affect the society's values, standards, and cultural outcomes (Moore, 1969, p.366).

Social change is characterized by complexity due to the multitude of factors intertwined with it, and perhaps the most important of them are as follows (Jaenini, 2009, pp: 198-200):

1- Scientific and technical progress as a result of new scientific theories and the growth of scientific ideas that led to modern inventions in various fields of life. Invention is a social process that includes a number of additions or modifications that have contributed to changing social life. Invention and discovery are important in bringing about social and cultural change. 
2- Environmental factors: Changes in the environment sometimes lead to a change in the way of life in different societies, and that the degree of influence on social life varies in different human societies.

3- The revolution and the emergence of leaders, thinkers and reformers: revolutions bring about comprehensive and rapid changes in life in its various fields, forward and perhaps sometimes backward, and the emergence of leaders, reformers and thinkers leads to changes in the prevailing systems, thinking and ways of life.

4- The immigration factor: social change may occur as a result of internal and external migration, which may lead to material, intellectual, economic and social changes.

5- Economic and technological factors: The economic factor, including its various activities, is considered one of the important factors in social change. Economic activities and relations have importance in social life, and the difference in production methods and the use of modern technology leads to a change in the way of life of people and increases in production processes.

6- Education is considered an important factor in social and cultural change, because the school and higher education institutions are acting on behalf of society in refining, educating and educating the personalities of generations. Success in achieving comprehensive development requires high-level education and a degree of sophistication.

7- Ideological factors: from new ideas and new philosophical trends that contribute to changing people's lives, work patterns and behavior, which leads to changes in social systems. Every change in ideology has to echo in social systems. History is replete with many intellectual movements that have caused profound changes in social and human systems.

8- Cultural friction between peoples, which means the spread of cultural elements from one community to another through the process of cultural communication, which leads to the transfer of many patterns of behavior and some universal values to other societies, which may contribute to many social changes. From this standpoint, contact between the peoples of the world is considered one of the important factors in enriching the human experience and an important factor in developing and benefiting from the experiences of others and employing the beneficial ones in bringing about social, cultural and educational changes.

9- Wars and conquests that lead to comprehensive changes in various aspects of social and cultural life. However, in most cases, these wars may lead to devastation and negative social changes.

10- The revolution in the world of communication and information, which made the world a small village, which affected the ways of life of people in general and the transmission of news and knowledge at a high speed, which led to profound and influential social, cultural and educational changes.

In sum, social change is the change that occurs in the patterns of life and social relations, which translates to how a social phenomenon loses its ancient features in different times, and it is a social process. Social change includes: small partial change and large total change, progressive change and regressive change, slow gradual change and sudden revolutionary change, temporary change and permanent change, automatic change and planned change.

The problems raised by the empirical study of social change are extremely difficult. Historical data is always incomplete or biased, and studying changes over a long period is often costly and difficult. Among the tools that researchers of social change rely upon are official statistics, frequent surveys and tracer studies. (Lailah et al., 2015)

Education is considered the most significant agency of learning social values. Therefore, educational institutions play the role of agent in socialization of the individuals. There are three aspects namely change agents, subject matter for bringing about social change and the cultural background of learners while declaring education as a gadget of social change.

Education is the process during which knowledge is acquired, skills are developed, values and traits are internalized through experiences. Education is an important source of economic and technological development in a society to create a true democratic atmosphere. For economic and social development, the individuals are expected be skill full, knowledgeable and competent and should have human values. Educational process ensures the mentioned requirements of the economic progress of a society.

Social change in a society is defined as the change in the minds and habits, belief systems, life styles, culture of the people. These changes occur due to globalization, rapid developments in science and technology, changes in the workplace and changes of the roles of the state.

There is a significant relationship between social change and education that education makes the individuals useful citizens, self-reliant and independent learners through providing opportunities to experience citizenship, self-reliance and independence. These characteristics are supportive of social change.

The people who acted as social reformers in social structure were educated who emphasized to change negative practices such as caste restrictions, inequality between male and female. They also emphasized others to eradicate socially evil customs and traditions. They worked for equality of male and female, improve governance of the state, establish democratic culture in institutions. Liberal philosophy was taught by them in order to bring about social change in society. Thus, education is regarded as a catalyst to spread social values in order to prepare individuals for social change during which unnecessary social practices could be minimized. Through education 
economy increase, justice is distributed, people participate in decision-making, and scientific technology is adopted in industries, agriculture and other professions, which lead towards modernization. The relationship between education and social change is mutual. Sometimes, social change influences changes in educational processes. For example, development in information technology influences educational system as now a day assessment system is based on information technology skills. Much software has been developed which is widely used in education. The good example of it is the use of multimedia for presentations in educational institutions.

Education plays an important role in social change as it carries on the everlasting values among the individuals in society these values then become the base for social change. For example, internet has revolutionized the world through which people within a very short time obtain useful and required knowledge on certain topics. Therefore, education highlights the values of using internet and enables the individuals use internet for their benefits.

Women empowerment is a type of social change which is because of educating the masses regarding the importance of women empowerment. Through empowerment women are given with equal status, rights and opportunities to step forward. It was because of the change in minds and beliefs of the people that education of females is considered important as education of male. This social change has taken palace because of awareness due to education. Education makes it possible to improve social and economic status of women. On the other hand, social change has made visible that education of females is important to develop the society economically and socially. The people get motivated towards female education due to the change of status of women and their benefit for the society. Thus, social change creates opportunities for education.

The role of education in decreasing rate of population growth is remarkable. Education plays the role of most effective contraceptive. The knowledge of regulating fertility through contraception increases with increasing number of school years for girls. Females having jobs spend more time in their workplaces but less time available for children and much greater incentive to have few children. Time required to receive education also delays the age of marriage. Education also empowers and liberates females willing to use modern contraceptive methods, to convince their husbands to decide on small family norms and to speak out openly to defend their reproductive rights. There is link between education and family planning.

In short, education develops capacities of the individuals to accept social change. After social change its impact is evaluated through the techniques which are guided by education. Education helps people to understand no constructive traditions and practices to be avoided and constructing new practices to be adopted which leads towards social change.

\section{Statement of the study:}

The problem of the study is the attempt to uncover the role of educational thought in social change in Jordan from the point of view of educational experts because it is assumed that the educational thought has a special role in the positive social change among the members of society, as educational and social studies agree that there is a relationship, whether it is directly or indirectly, between changes in the social and economic environment and between the structures of education and the types of educational activity. This is because education, in terms of its function, contributes to changing societies through its contribution to the awareness of its own problems, and the attempt to solve them and create a sound educational social environment for positive social changes, and specifically, the problem of the current study is to answer the following questions:

What is the Jordanian educational thought from the viewpoint of the Jordanian educational experts?

What is the role of educational thought in social change in Jordan, the viewpoint of Jordanian educational experts?

\section{Objectives of the study:}

This study aimed to identify:

- The opinions of educational experts on educational thought in Jordan

- The role of educational thought in making social change in Jordan

\section{Significance of the study:}

The importance of the study comes from the importance of its subject. As its importance is evidenced by the modern cultural and educational need for such studies, which are concerned with revealing the role of educational thought in social change. Education to bring about intended social changes that make Jordan compatible with the social changes taking place globally while preserving its originality and its cultural and social distinction.

\section{Literature Review:}

Al-Omari (1992) conducted a study aimed to identify the educational philosophy of public school teachers in Jordan, and to test the relationship between the teacher's possession of a clear educational philosophy and a number of subjective variables for the teacher: gender, academic qualification, educational qualification, experience, and the level of the school in which he/she works at. The sample of the study consisted of (565) male and female teachers, who were randomly selected using the cluster-stratified method at the level of the Kingdom's schools. 
The researcher reached the following results:

- The percentage of male and female teachers who hold a specific educational philosophy is (44.2\%) only, while the percentage of those who do not carry a specific educational philosophy is (55.8\%).

- The vast majority of those who had a specific educational philosophy carried progressive philosophy (stemming from pragmatic philosophy), while the numbers that carried other philosophies were few.

- There were no statistically significant differences between the teacher's possession of an educational philosophy and any of the variables of gender, academic qualification, experience, and school level, while these differences were shown with educational qualification, as the teachers who have been trained in professional education knowledge are more likely to develop their own educational philosophy than their colleagues without training.

Abu Al-Sheikh (1998) conducted a study aimed at identifying the philosophical principles, concepts and trends that guide education in Jordan, their sources, and the ethical and ideological rules stemming from it. The study sample consisted of the training materials, which represent the physical community of the study, and it was chosen in the systematic, random stratified method, and the number of its components reached (17) material, which constituted $(37.8 \%)$ of the physical study population. Each guideline is categorized by the areas of philosophical principles to which it belongs. The study sample consisted of teachers who had undergone in-service training, and it was chosen by the systematic random stratification method. The sample size was (399) teachers. A test was applied represented by the general principles, moral and political rules guiding emanating from the philosophical principles of education in its various intellectual (ideological), patriotism, nationalism, social and humanitarian fields. The study found the following results:

- The Jordanian state is concerned with implementing a social philosophy that is defined by four frameworks: Islam and Arabism, the Great Arab Revolt, the Jordanian experience, and contemporary world civilization, which are general and unspecified frameworks, clearly defined. Therefore, a clear and specific educational philosophy has not yet been developed, and it continues its education according to general principles derived from its heritage, values and aspirations.

- The results showed the level of teachers' representation of the general guiding principles and ethical rules that there is a decline in the level of teachers' representation of them in general, and that there is a relatively high level of teachers 'representation of them in the fields of "intellectual principles and national principles". While there was a clear decline in the level of their representation in the areas of "national principles and humanitarian principles." Teachers' inactivity levels of the ethical and general political principles and rules guiding the philosophical principles of education in Jordan do not differ fundamentally according to their scientific and pedagogical qualifications, their experience in education, the classes and subjects they study, and the type of program or training programs they have undergone.

Al-Suhaimat (2003) conducted a study aimed at analyzing educational policies in the content of Jordanian official documents, in light of political, economic and social changes, and their reflection on educational development in Jordan, since the issuance of the Education Law No. (16) of 1964. The analysis process of educational policies in the field of public education was carried out in official documents, and in order for the study to achieve its purpose, it adopted the content analysis method, as well as the historical approach within the limits of the study's requirements, to investigate events in an inductive manner, using quantitative analysis methods to estimate the relative weights of education issues, and qualitative analysis in its various stages, With some temporal and methodological comparisons. The study reached several results, including: the clarity of the contents of official documents in their affirmation of a set of educational policy principles, which can be considered directed to educational trends and define its contents; The clarity of the impact of the political dimension, and its importance in crystallizing an intellectual vision on the principles of educational policies, and in their national, national, and humanitarian dimensions; The clarity of the impact of the economic and social dimensions in the analysis of the educational policy that contributed to determining the paths of the educational system; The clarity of the impact of local, regional and international events and the manifestations of the knowledge revolution, and its impact on the analysis of educational policies; Insufficient community participation, lack of data, and weak scientific research, whether at the level of public systems and policies, or in the educational field; The clarity of some educational development in the quantitative and qualitative aspects, with reference to some of the shortcomings of this development in light of the various previous variables.

Bani Amer (2006) conducted a study aimed at identifying the educational thought and educational policies of Hashemite leaders and their role in social development (1921-2005). The content analysis method is used as the views and ideas of Hashemite leaders are demonstrated by extrapolating them from their books, statements, speeches, and audio interviews and visual. The researcher concluded that the Hashemite leaders (1921-2005) carry educational ideas in the elements of social philosophy and the educational process, aiming to change the social reality, liberate the human being, and build it according to his needs, and the needs of the society to which he belongs, represented in: the divine self, reason, and education And its goals, teacher and learner, democracy, values, work and devotion to it, Arab nationalism, and women; And that the educational thought of Hashemite leaders has a positive influence in establishing educational policies. And that the educational thought and educational policies 
of the Hashemite leaders have worked to bring about social development in the Jordanian society in various aspects of life, represented by: an educational renaissance, providing a decent life for the citizen, developing scientific and creative thinking and using technology, consolidating democracy, and addressing society's problems of poverty, hunger and disease. And deepening belonging to the local, Arab, Islamic and international community.

Al-Qudah, Al-Zaabi and Al-Hilat (2008) conducted a study aimed at knowing the role of higher education in social mobility in Jordan from the students 'point of view, as the study sample numbered 541 students from public and private universities and community colleges in Jordan. The means and standard deviations and 0ne- way ANOVA were used. Also Scheffe statistics test was used to see if there are statistical significant differences. Results of this study indicated that a strong association was found between level of high education and social mobility from students prospective. Also the statistical analyses revealed that community colleges and under graduate student regarding the role of High Education on the Social Mobility was statistically significant $(p<0.05)$ compare with graduate students respectively. While there were no statistically significant differences in students prospective toward the role of high education on the social mobility pertaining the type of university (governmental and private), family income, and sex role.

Badarneh and Al-Hawary (2015) conducted a study aims to identify the degree of practicing principles of educational philosophy by teachers of basic stage at Irbid first educational directorate as perceived by them and by supervisors and Principals. The population of this study consisted of all supervisors, Principals, and teachers at Irbid First Educational Directorate, and numbered (4706), distributed as follows: (54) supervisors, (146) principals, and (4506) teachers. The researcher applied the study tool on all supervisors and principals, while a random sample of teachers totaling (450) was chosen, representing $10 \%$ of the population. In order to achieve the aims of this study the researcher prepared and developed a questionnaire consisted (39) items, distributed in five domains: (intellectual principles, national principles, regional principles, humanitarian principles and social principles). Those domains were prepared according to the Educational philosophy in Jordan, No. (3) for the year 1994. The findings of the study were:

- The degree of practicing principles of educational philosophy by teachers of basic stage showed a high degree, with an (4.06) average. The (national principles) domain was listed on the top.

- There are statistical significant differences at the significance level of $(\alpha=0.05)$ among the responses of the study sample on all domains of principles of educational philosophy, due to (gender) variable, in favor of (females). - There are no statistical significant differences at the significance level of $(\alpha=0.05)$ among the responses of the study sample due to (scientific qualification, experience) variables.

\section{Methodology: Approach:}

The researchers of the present study adopted a qualitative approach to explore the reality of educational thought in Jordan and its role in making social change in Jordan from the experts' perspective. They adopted a constructivist paradigm. Constructivist researchers focus on understanding and reconstructing the meanings that people (including the research) hold about the phenomenon being studied (Guba\& Lincoln, 1994) Constructivists create knowledge through interaction between the researchers and participants, using dialogue and reasoning as primary methods of investigation. To meet the study's goals, in-depth interviews were conducted with the participants.

\section{Participants:}

6 male experts in the field of education who were selected for participants in this study since they would be "knowledgeable informants" (Lincoln\&Guba, 1985, p.234). Since the goal of the study was to uncover Jordanian educational thought and its role in making social change, it was important that participants had enough information and experience in Jordanian education sector. To be more specific, among those participants there are: a former minister of the Ministry of Education, 3 faculty members specialized in education and 2 university presidents.

\section{Data collection methods:}

The primary sources of data for this study were in-depth interviews and field notes.

\section{Interviews}

The researchers aimed to collect data through conducing qualitative in-depth interviews.

For this study, all interviews were conducted face to face, as a first step in the interview process, participants were reminded of the purpose of study, research procedures, and protection of confidentiality. With participant approval, in interviews were audio- recorded to ensure a complete transcript. Field notes were taken during all interviews, enable the researchers to track key points to later in the interview and for use during later data analysis.

Participants were given the interview questions at least a week before their interview appointment, so they would have time to prepare. The interview questions follow a semi- structured shape but questions were passed to 
10 experts who work as faculty members in the faculty of educational sciences at the University of Jordan to make sure they were appropriate. Experts were asked to assess those questions in terms of clarity, and relevancy to the goals. They were asked to make deletions and additions. All the experts suggested that the questions are clear and relevant to the goals of the study. In the light of the experts' comments, changes were made. The final version of the interview questions was drafted. It consists from 8 questions.

\section{Field notes}

Field notes served as a supporting data source for current study. Field notes were typed during each interview and later analyzed and compared to the interview transcriptions (Maxwell, 2005). During each interview in this study field notes were taken by the researchers to be analysed together with interview transcriptions.

\section{Data analysis:}

The data was analysed using content analysis after interview transcripts were reviewed several times and coded with the help of a qualitative data analysis software. Codes and categories were developed and emerged using the constant comparative method (Glaser \& Strauss, 1967), then the researchers went back to the field notes and compared them with the analysis and developed the final categories to themes.

\section{Limitations:}

Limitations of this study related to the sample, first the number of participants in the study (6) was small, a lager amount of participants may have produced different and additional themes. Secondly, the lack of female participants in this study may affect the results of this study to some extent, but at the same time, the tyranny of the male right of expression and their control over important academic and administrative positions seem to be reality in current Jordanian society.

\section{Results:}

Three distinct themes emerged from the research data. The major themes identified from the results of this study included:

1. Understanding of the term "educational thought"

2. Reality of educational thought in Jordan from the experts' perspective

3. Role of educational thought in social change in Jordan

Theme 1 and 2 answered the first research question; what is the reality of educational thought in Jordan? Theme 3 addressed the second research question; what is the role of educational thought in social change in Jordan from the perspective of experts?

\section{Theme 1: Understanding of the term "educational thought"}

The participants are accustomed to giving a definition of the concept of the topics covered at the beginning of the discussion about them, and a statement of what educational thought is from their point of view, by addressing its content, owners, standards and roles, and these definitions and concepts presented can show us the participants' understanding of what educational thought is. In fact, how educational thought is understood is the basis for talking about the role of educational thought. It also prepares us for the subsequent analysis of the role of educational thought in social change.

5 of the 6 Jordanian participants gave a definition of educational thought directly or indirectly during the interviews. The characteristics of understanding the educational thought among the Jordanian participants emerged as follows:

1- All participants emphasized the importance of educational thought in refining the human personality for the better and building a complete person, and it has an important role in changing society.

2- The participants (a, c \& d) suggested that the proprietors and promoters of educational thought are the top educators, or the so-called people of experience and expertise in the educational field only.

3- The participants emphasized the importance of foundations and constants for educational thought, and the most important constants from their point of view is ideology and religion, or what he sometimes calls the philosophy of society, or the spiritual and social foundations sometimes among some of the participants. About these foundations and role of educational thought in general Participant (b) stated: "But it may be negative sometimes if this educational thought is distorted in the sense that the thought is not based on sound and correct foundations. You know that educational thought is based on a philosophical basis, a social basis, a cognitive basis and a psychological basis. All these foundations have the largest role in building this thought. If the educational thought is based on these foundations, we could say that it is a correct thought, and it will have a positive role in changing. But if this thought is not clear and not based on foundations, we cannot call it thought, it is not an educational thought."

In sum, the Jordanian educational thought in the viewpoint of the participants is of an eclectic nature, although 
some do not acknowledge the existence of a Jordanian educational thought, and this indicates the lack of clarity of thought in form and content. However, after the dialogues, we have constructed an understanding of Jordanian educational thought, and came to the conclusion that the Jordanian educational thought is a selective thought that benefits from global educational thought in general and western educational thought in particular with respect of the Islamic principles.

\section{Theme 2: Reality of the (educational thought) in Jordan from the experts' perspective}

An interesting phenomenon was discovered during the interviews that 3 Jordanian participants verbally confirmed their belief that there is no Jordanian educational thought, and showed their dissatisfaction with the current situation. In addition to two participants who mentioned the existence of a Jordanian educational thought "on the paper", which is a thought that is based on "Islamic thought, a thought that accepts the others, a thought that accepts criticism", and "the constants on which it is based stem from the Islamic faith, the Jordanian constitution, and the principles of the Great Arab Revolt."

4 interviewees suggested that the dominant educational thought in Jordan is affected by the western ideologies and thoughts due to globalization. However, western ideologies and thoughts are inconsistent with the local culture and Islamic principles sometimes.

For instance, participant (a) suggests that the contemporary educational thought in Jordan isn't well-developed. That is because Jordan is still a developing country that needs to achieve more development. In fact, all types of thoughts in Jordan must be developed. The same applies to all developing countries. It also applies to all the Arab countries (Participant (a)).

Participant (c) suggests that the contemporary educational thought in Jordan isn't clear.

Participant (e) states the following: 'I believe that there isn't any clear educational thought nor strategy in Jordan currently. The outcomes of the Jordanian educational institutions and the Jordanian educational systems prove that. In fact, the contemporary educational thought in Jordan isn't linked to the socio-economic development ". Based on the views of participants, the contemporary educational thought in Jordan isn't clear nor well-developed. All the respondents aren't satisfied with the contemporary educational thought in Jordan.

Participant (b) suggests that the Islamic thought cannot be fully promoted during the contemporary age. Thus, the contemporary educational thought in Jordan is moderately influenced by the Islamic thought.

"Now, I cannot take everything that came with Islamic philosophy and apply it in the Jordanian educational system. For example, Islamic philosophy says that an educator or teacher does not take a salary for teaching. So we take the framework of pragmatic philosophy, it is necessary to have benefits for teaching." (Participant (b))

Based on the views of most of the interviewees, the contemporary educational thought in Jordan is affected by various trends. It is affected by the fundamentals of the Islamic religion and the traditions and the customs of the Jordanian society. It is affected by the Western thoughts, due to Jordanian international students seeking for knowledge in western countries. After those students return to their homeland (i.e. Jordan), they shall promote western ideologies and thoughts in the Jordanian society. Non-profit global organizations -e.g., UNESCO - seek promoting western educational thoughts through their proposed developmental programs.

For instance, participant (a) suggests that the contemporary educational thought in Jordan is affected by the western thought. He adds that such influence is attributed to having many US aids provided for supporting Jordan in educational areas (participant (a)).

Participant (c) suggests that the contemporary educational thought in Jordan is a mixture of various thoughts and ideologies. Such a mixture includes the western thought (participant (c)).

Participant (d) adds:

"I believe that the contemporary educational thought in Jordan is a mixture of thoughts, way of thinking, cultures, and ideologies". This mixture includes the Islamic, capitalist, realistic, and naturalistic ideologies. The contemporary educational thought in Jordan is consistent with the principles of the Islamic religion. " (Participant $(\mathrm{d})$ )

Theme 3: Role of the (educational thought) in making social changes in Jordan from the experts' perspective There is a disagreement in this regard among respondents. Some respondents believe that educational thought in Jordan has been playing a significant role in making social changes in Jordan. Some respondents believe that educational thought in Jordan hasn't been playing a significant role in making social changes in Jordan.

Participant (a) suggests that the contemporary educational thought in Jordan has been playing a minor role in making social changes in Jordan. He adds that educators haven't been playing a significant role in Jordan.

"In my opinion, it is a modest role, not a basic and important role as much as politicians and intellectuals play. The change in the Jordanian reality is played by an act of transition from a traditional society to a modern society. This does not, of course, deny that educational thought has a role, but from my assessment that it is humble and that it is a limited role in general." (Participant (a)) 
Participant (f) suggests that the educational thought in Jordan led to making positive social changes. He adds that educational thought in Jordan led to making positive changes to people's values. Such positive changes led to achieving advancement in society (participant (f)).

Participant (d) suggests that the dominant educational thought among faculty members and teachers in Jordan led to promoting democracy in society. He adds that this thought led to changing Jordanians' way of thinking and priorities. For instance, Jordanians today show much respect to teachers and using technology. They reject physical punishment. They seek achieving equality in terms of educational opportunities (participant (d)).

Participant (d) adds that social change has been occurring rapidly due to globalization.

According to participant (e), educational thought led to the occurrence of negative and positive social changes in the Jordanian society. According to participant (a), such positive changes include: the change in the role of women in the Jordanian society. Today, women in Jordan can participate in many political, social and economic areas. In addition, many Jordanian women today are working and receive post-graduate degrees (participant (a)).

According to participant (b), educational thought in Jordan led to a change to what is considered taboo in professions. For instance, many Jordanian families today encourage their sons to become a car mechanic or practice a hand craft in the future. However, in the past, practicing this profession wasn't socially accepted by many Jordanian families. In addition, many Jordanian families today let their daughters get married to men who may be car mechanics or practicing a hand craft. However, in the past, many Jordanian families didn't let their daughters get married to those men (participant (b)).

According to participant (b), the dominant educational thought led to providing more attention to getting postgraduate degrees. For instance, many parents seek providing their children with the best education, thought they are illiterate (participant (b)). According to participant (a), educational thought led to promoting political awareness and democracy in the Jordanian society.

The negative social impacts of educational thought in Jordan include loss of the Jordanian identity due to participant (c). In other words, "Jordanians' way of eating, talking and sitting are influenced today by the ones living in western societies".

The educational thought in Jordan also led to negative social change. Such negative changes include as follows: negative changes in the way family members treat each other, negative changes in social behaviors and values, in addition to unplanned educational programs which increased the unemployment rate (participant (e)).

\section{Discussion}

The results differ slightly from the Badarneh and Houry (2015) study, which referred to a high degree of degree of practicing principles of educational philosophy by teachers of basic stage, with an (4.06) average with the (national principles) domain listed on the top.

However, the results are in agreement with the qualitative McKeown (2015) study which reported "All teachers in public school did not have a clear grasp of the objectives or philosophy of the education system, Most of them actually confused when asked about these and were unable to formulate answers." (McKeown, 2015) This implies that the situation that experts have mentioned in this study is not rare and without roots, but a common phenomenon among Jordanian educators even from most basic level teachers to higher administration and education plan departments.

\section{Conclusion:}

Regarding the reality of the (educational thought) in Jordan, the dominant educational thought in Jordan today is affected by the western ideologies and thoughts due to globalization. However, it should be based on the Islamic thought, Jordanian Constitution, and principles of the Great Arab Revolt. The dominant educational thought in Jordan today isn't clear nor well-developed. Thus, it is expected to be developed.

Educational thought in Jordan led to making several positive social changes, such positive changes include as follows: change in the value, moral, behavioral and economic system, a much more positive attitude towards education of woman, a change to what is considered taboo in professions, however, the social change that occurred in the Jordanian society influenced by its education development is limited. Meanwhile negative changes such as loss of Jordanian identity and unemployment is deeply concerned.

\section{References}

- Al-Abdullah, Latouf. (2011). The Development of Arab Educational Thought (The Arab Organization for Education, Culture and Science as a Model), The Arab Foundation for Scientific Consulting and Human Resources Development, Cairo.

- Abu Al-Sheikh, Mustafa. (1998). Philosophical principles in Jordan and the role of teacher training in achieving them, unpublished PhD thesis, University of Jordan: Amman, Jordan.

- Al-Omari, Khaled. (1992). The Educational Philosophy of the Jordanian Teacher, Mu'tah Journal for Research and Studies, Issue (23), Volume (7), pp. 14-39. 
- Al-Qudah, Mohammed \&.Al-Zaabi, Ahmad \& Al-Hilat, Mustafa. (2008). Role of High Education on the Social Mobility from Students. Mutah Journal (Humanities and Social Sciences Series). 23. 27-46.

- Al-Suhaimat, Ahmad. (2003). An Analytical Study of the Educational Policies in the Light of the Political, Economic, and Social Changes, and their Impact on the Educational Development in Jordan, unpublished $\mathrm{PhD}$ thesis, Amman Arab University for Graduate studies.

- Badarneh, Hazem Ali \& Al-Hawary, Hazem Ahmed. (2015). The Degree of Practicing Principles of Educational Philosophy by Teachers of Basic Stage at Irbid First Educational Directorate as Perceived by Them and by Supervisors and Principals. Dirasat Educational Sciences. 42. 927-946.

- $\quad$ Bani Amer, Mohammed Rashid. (2006). Educational thought and educational policies of Hashemite leaders and their role in social development (1921-2005), unpublished PhD thesis, Yarmouk University.

- $\quad$ Ginsberg, M. (1958). Social Change, British Journal of Sociology, vol.4, pp 205-209.

- $\quad$ Glaser, B.G., \& Strauss, A.M. (1967). The discovery of grounded theory: Strategies for qualitative research. New York, NY: Aldine.

- Guba, E.G., \& Lincoln, Y.S. (1994). Competing paradigms in qualitative research. In N.K. Denzin \& Y.S. Lincoln (Eds.), Handbook of qualitative research (pp.105-117). Thousand Oaks, CA: Sage.

- Jaenini, Naeem Habib. (2009). Sociology of Contemporary Education between Theory and Practice, Wael Publishing and Distribution House, Amman.

- $\quad$ Layla, Ali Mahmoud \& Al jawhari, Muhammad \& Shukri, Alya. (2015). Social and Cultural Change, Dar Al-Masirah for Publishing, Distribution and Printing, 2nd Edition, Jordan: Amman.

- $\quad$ Lincoln, Y.S., \& Guba, E.G. (1985). Naturalistic inquiry. Newbury Park, CA: Sage Publications, Inc.

- Maxwell, J.A. (2005). Qualitative research design (2nd ed.). Thousand Oaks, CA: Sage Publications, Inc.

- McKeown, Megan. (2015). "Peace Building through Education Reforms Case study: Objectives and Philosophy of Jordanian Educational System", Independent Study Project (ISP) Collection. 2058. https://digitalcollections.sit.edu/isp_collection/2058

- Moore, W. E. (1969). "Social Change", in: D.J. Sills (ed.) International Encyclopedia of Social Sciences, Vol.14. Macmillan, New York.

- Sharif, Mustafa. (1940). Islamic Educational Thought, Teacher and Student Magazine, Department of Education, UNRWA, Amman. 